Dieses Dokument ist eine Zweitveröffentlichung (Postprint) /

This is a self-archiving document (postprint):

Jason Melidonie, Junzhi Liu, Yubin Fu, Jan ]. Weigand, Reinhard Berger, Xinliang Feng

\title{
Pyrene-Fused s-Indacene
}

Erstveröffentlichung in / First published in:

The Journal of Organic Chemistry. 2018, 139 (48), S. 6633 - 6639. ACS Publications. ISSN 1520-6904.

DOI: https://doi.org/10.1021/acs.joc.8boog25

Diese Version ist verfügbar / This version is available on:

https://nbn-resolving.org/urn:nbn:de:bsz:14-qucosa2-365766 


\section{Pyrene-fused s-indacene}

Jason Melidonie, ${ }^{\dagger}$ Junzhi Liu, ${ }^{\dagger}$ Yubin Fu, ${ }^{\dagger}$ Jan. J. Weigand, ${ }^{\ddagger}$ Reinhard Berger ${ }^{\star}{ }^{\dagger}{ }^{\dagger}$ and Xinliang Feng*, ${ }^{\dagger}$

${ }^{\dagger}$ Center for Advancing Electronics Dresden (cfaed) and Faculty of Chemistry and Food Chemistry and ${ }^{\ddagger}$ Chair of Inorganic Molecular Chemistry, Technische Universität Dresden, o1062 Dresden, Germany. "Corresponding authors: xinliang.feng@tu-dresden.de and reinhard.berger@tu-dresden.de.

Supporting Information Placeholder

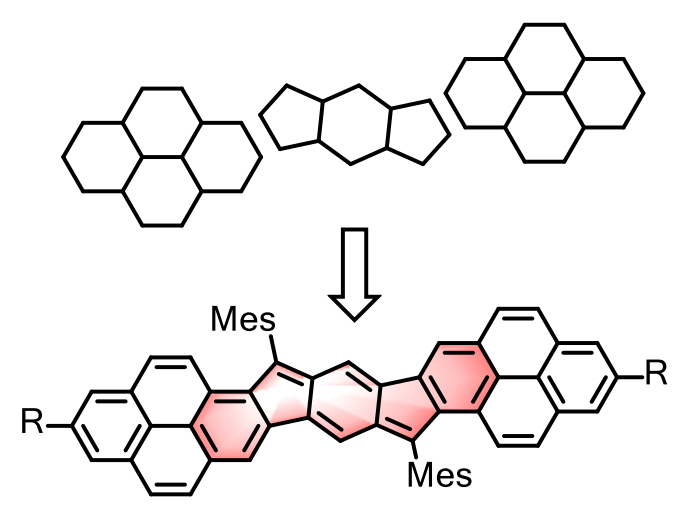


ABSTRACT: One antiaromatic polycyclic hydrocarbon ( $\mathrm{PH})$ with and without solubilizing tert-butyl substituents, namely $s$-indaceno[2,1-a:6,5-a']dipyrene (IDPs), has been synthesized by a four-step protocol. The IDPs represent the longitudinal, peri-extension of the indeno[1,2-b]fluorene skeleton towards a planar $40 \pi$-electron system. Their structures were unambiguously confirmed by X-ray crystallographic analysis. The optoelectronic properties were studied by UV/Vis absorption spectroscopy and cyclic voltammetry. These studies revealed that peri-fusion renders the IDP derivatives with a narrow optical energy gap of $1.8 \mathrm{eV}$. The maximum absorption of IDPs is shifted by $160 \mathrm{~nm}$ compared to the parent indenofluorene. Two quasi-reversible oxidation as well as reduction steps indicate an excellent redox behavior attributed to the antiaromatic core. Formation of the radical cation and the dication was monitored by UV/Vis absorption spectroscopy during titration experiments. Notably, the fusion of $s$-indacene with two pyrene moieties lead to IDPs with absorption maxima approaching the Near Infrared (NIR) regime.

\section{INTRODUCTION}

Polycyclic hydrocarbons (PHs) featuring antiaromaticity have been in the focus of research for decades because of their unique electronic structure and the related magnetic, photophysical and electronic properties. ${ }^{1}$ In contrast to polycyclic aromatic hydrocarbons (PAHs) their absorption maxima are significantly bathochromic shifted as the energy difference of their frontier orbitals is significantly reduced and comparable to those of the acene series. ${ }^{2}$ The narrow optical energy gap renders antiaromatic PHs promising materials for application in optoelectronic devices.3, 4 The most common way to obtain antiaromatic, $\pi$-conjugated structures is embedding a $s$-indacene moiety into the core of a $\pi$ conjugated framework in which a quinodimethane (QDM) subunit is found. 5 This strategy has been widely used to synthesize antiaromatic but also proaromatic $\mathrm{PHs}$ with partial diradical character. ${ }^{6}$ Several ortho-, 7 meta- ${ }^{8}$ and para-QDM9 structures have been synthesized in the past years by $\mathrm{Wu}$, Tobe and Haley whereby $m$ - and $o$-structures are considered as highly reactive due to their increased open-shell character compared to their $p$-analogues. Typical p-QDM representatives are diphenalenes ${ }^{10}$ and octazethrenes ${ }^{11}$ which feature a biradical character up to $0.68,{ }^{12}$ as well as indeno[1,2b]fluorenes (IF, red sub-structures in the formula displayed in Figure 1$)^{2}$ which can be regarded as benzo-fused $s$-indacenes with an usually insignificant biradical character.13 Therefore, IFs are considered as stable closed-shell systems. Moreover, indeno[1,2-b]fluorene shows notable resistance towards air, light and heat when protective substituents such as mesityl (Mes) at the reactive 6- and 12-positions are introduced. ${ }^{14}$

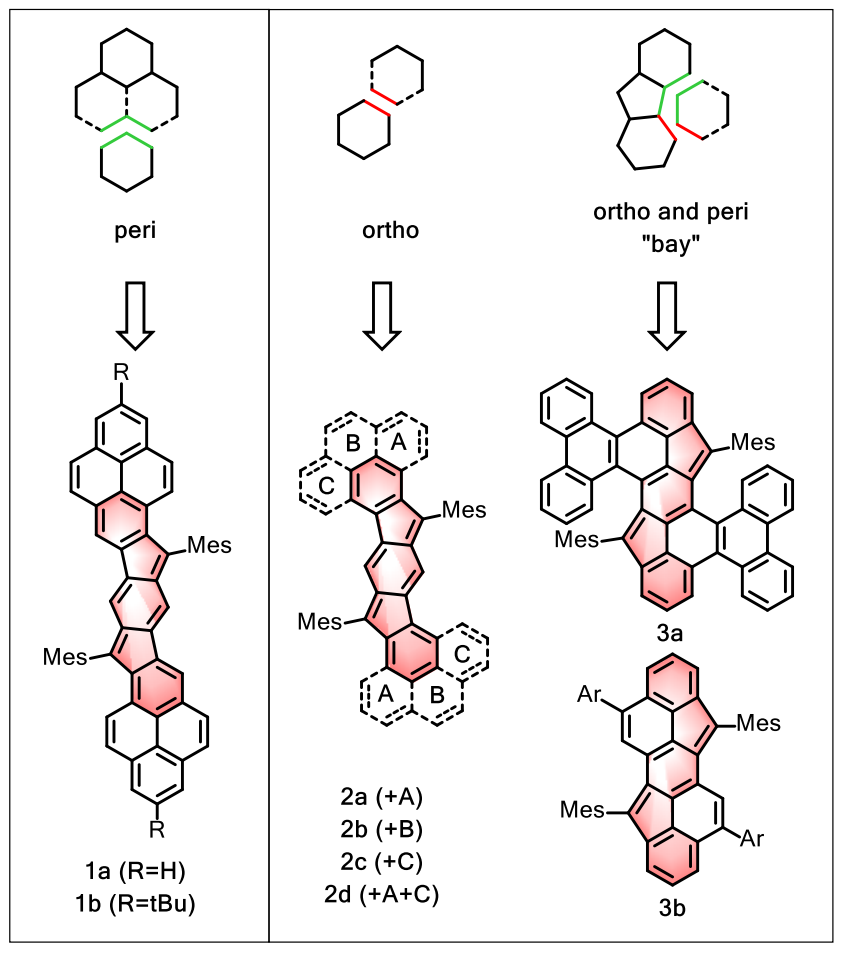

Figure 1. Representation of the different fusion-patterns for IF; in addition to ortho- and ortho-peri-extension in $\mathbf{2 a - d}$ and 3a,b we present peri-fusion by formally adding phenalene units to indeno[1,2-b]fluorene.

The stability enables processibility for potential application in organic field-effect transistors (OFETs), photovoltaics (OPVs) and light-emitting diodes (OLEDs). ${ }^{15-17}$ To further tune their optoelectronic properties, several longitudinal extended indenofluorenes have been synthesized by Haley. As exemplified in Figure $\mathbf{1}$, in these derivatives, the benzene rings for $\mathbf{2 a - \mathbf { d } ^ { 1 8 }}$ and also heteroatom containing analogs are fused in ortho-fashion to the parent IF.19-21 Recently, our group reported also lateral ortho-peri - along the "bay-position" -extended indeno[1,2-b]fluorenes $\mathbf{3 a , b}$ resulting in twisted geometries. ${ }^{22}$ In contrast to ortho- (2a-d) and ortho-periexpansion (3a,b) whereby conjugation is extended only over two bonds (indicated by the dashed bonds in Figure 1), peri-fusion of PAHs extends the conjugation along three directions and, thus, a significant effect on the optoelectronic properties is expected. 9

\section{Scheme 1. Synthesis of ra,b.}




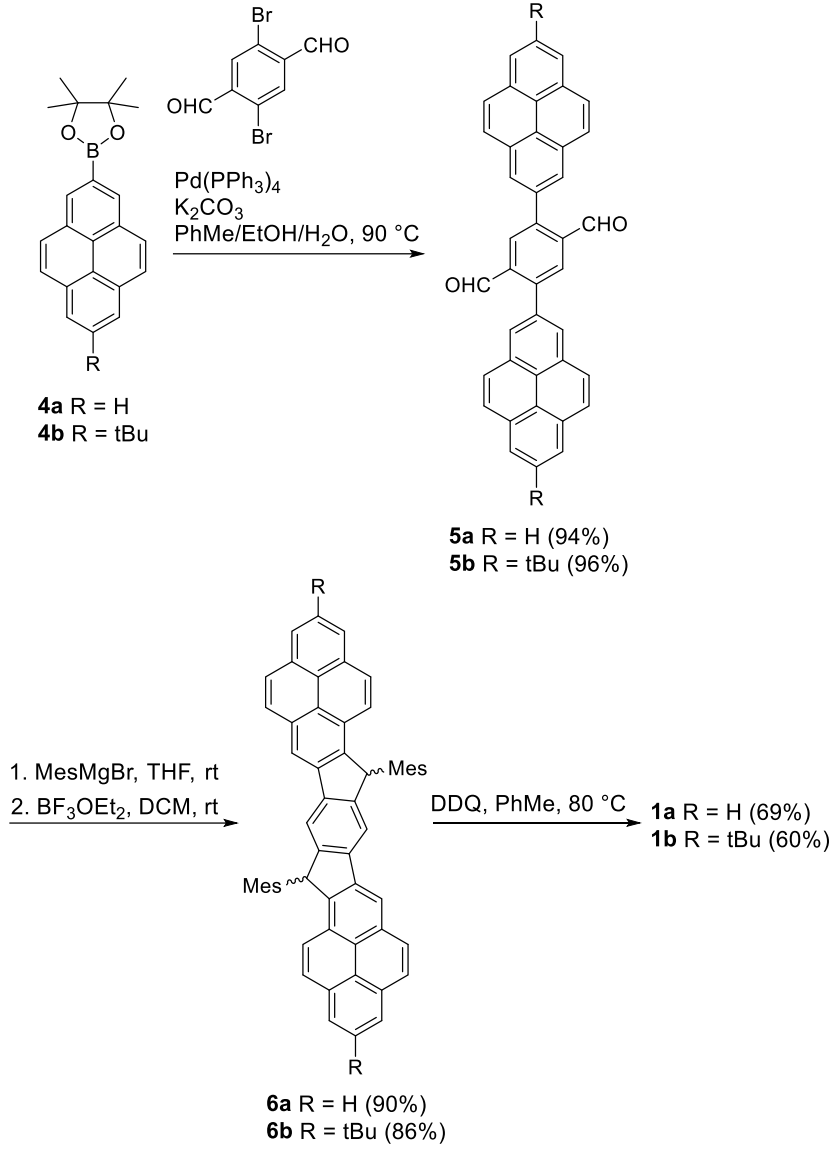

\section{RESULTS AND DISCUSSION}

In this work, we report a scalable four-step synthestic route to $s$-indacenodipyrenes (IDPs), namely 8,18 dimesityl-s-indaceno[2,1-a:6,5-a']dipyrene (1a) and 2,12-ditert-butyl-8,18-dimesityl-s-indaceno[2,1-a:6,5-a']dipyrene (1b). Formal peri-fusion causes a red shift of $\sim 160 \mathrm{~nm}$ of the maximum absorption from $512 \mathrm{~nm}$ for parent IF to $676 \mathrm{~nm}$ for $1 \mathbf{a}$ and $682 \mathrm{~nm}(\mathbf{1 b})$, thus approaching the NIR region. ${ }^{14}$

The targeted IDPs $\mathbf{1 a}$ and $\mathbf{1 b}$ were synthesized starting from 4,4,5,5-tetramethyl-2-(pyren-2-yl)-1,3,2dioxaborolane (4a) or 2-(7-(tert-butyl)pyren-2-yl)-4,4,5,5tetramethyl-1,3,2-dioxaborolane $(\mathbf{4} \mathbf{b})$, which were both easily accessible by $\mathrm{C}-\mathrm{H}$ borylation of pyrene developed by the group of Marder (Scheme 1 ). ${ }^{23}$ Suzuki reaction of $\mathbf{4 a} \mathbf{a}, \mathbf{b}$ and 2,5-dibromoterephtalaldehyde ${ }^{24}$ provided linear 2,5di(pyren-2-yl)terephthalaldehyde (5a) and 2,5-bis(7-(tertbutyl)pyren-2-yl)terephthalaldehyde $\quad(\mathbf{5 b})$. Crude compounds $\mathbf{5} \mathbf{a}$ and $\mathbf{5} \mathbf{b}$ were suspended in THF and treated with mesityl magnesium bromide. Without further purification, Friedel-Crafts reaction induced by boron trifluoride diethyl etherate afforded the highly blue fluorescent precursor molecules, 8,18-dimesityl-8,18dihydro-s-indaceno[2,1-a:6,5-a']dipyrene (6a) and 2,12-ditert-butyl-8,18-dimesityl-8,18-dihydro-s-indaceno[2,1$a: 6,5-a^{\prime}$ ]dipyrene $(\mathbf{6 b})$ in a yield of $90 \%$ and $86 \%$ over two steps, respectively. In the final step, treatment of $\mathbf{6 a}$ and $\mathbf{6} \mathbf{b}$ with 2,3-dichloro-5,6-dicyano-1,4-benzoquinone (DDQ) in dry toluene afforded the desired products $\mathbf{1 a}$ and $\mathbf{1 b}$ as green solids in yields of $69 \%$ and $60 \%$, respectively, after filtration over aluminum oxide and subsequent precipitation in methanol. Both targeted compounds showed reasonable solubility $\left(1.3 \mathrm{mgml}^{-1}\right)$ in toluene and tetrachloroethane. Two-dimensional NMR spectroscopy $\left({ }^{1} \mathrm{H} /{ }^{1} \mathrm{H}\right.$-COSY/NOESY, see Supporting Information Figure S9-S12 and $\mathrm{S}_{\left.16-\mathrm{S}_{17}\right)}$ allowed a full proton assignment of $\mathbf{1 a}$ and $\mathbf{l b}$ after the addition of hydrazine to remove trace radical impurities. ${ }^{25}$

a)

b)
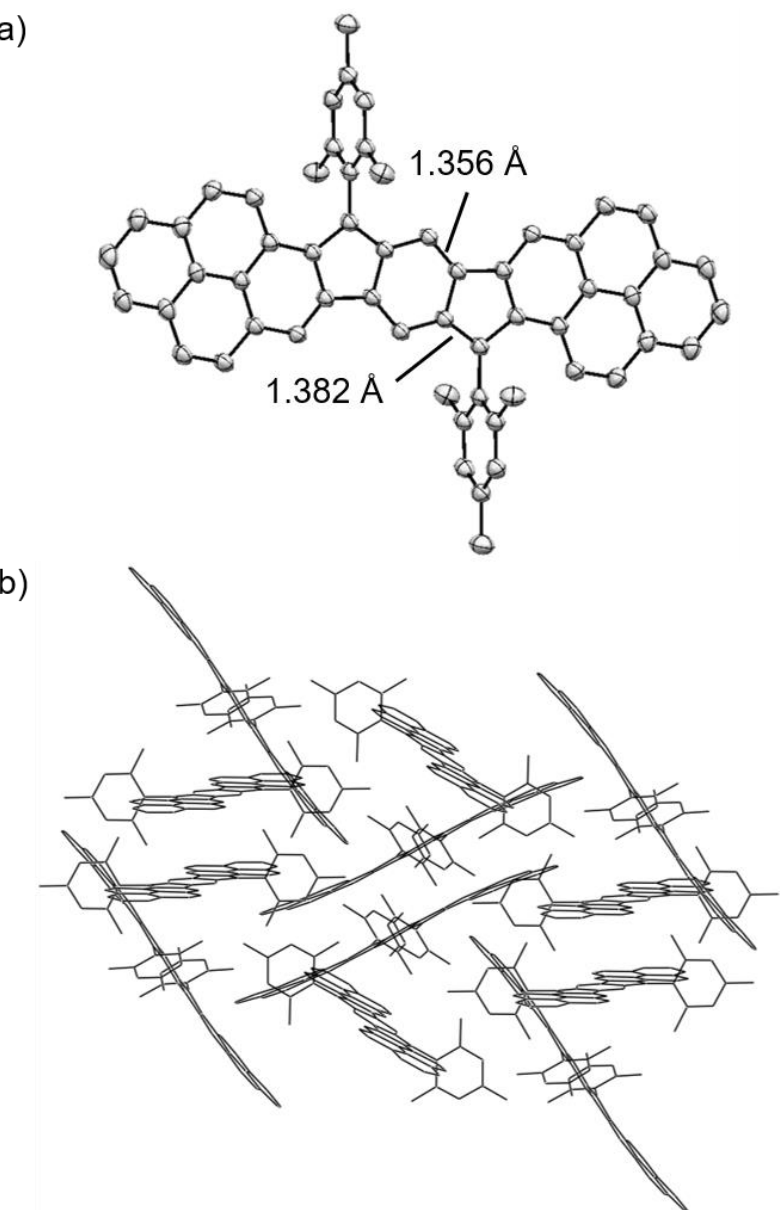

Figure 2. Molecular structure (a) and packing in solid state (b) of 1a; hydrogen atoms are omitted for clarity and the thermal ellipsoids are displayed at a 50\% probability.

Single crystals of $\mathbf{1 a}$ and $\mathbf{1 b}$ suitable for X-ray analysis were obtained by slow evaporation of their solutions in a $\mathrm{CS}_{2} / n$-hexane mixture and their molecular arrangements were unambiguously confirmed. Both compounds 1a (Figure 2) and $\mathbf{1 b}$ (Supporting Information Figure S18) possess a planar $\pi$-conjugated carbon skeleton and a $C_{2}$ point symmetry. The central core possesses two short $\mathrm{C}\left(\mathrm{sp}^{2}\right)-\mathrm{C}\left(\mathrm{sp}^{2}\right)$ bonds (1.356(2) and 1.357(2) $\AA$ for $\mathbf{1 a}$ and $\left.\mathbf{1 b}\right)$ and four long $\mathrm{C}\left(\mathrm{sp}^{2}\right)-\mathrm{C}\left(\mathrm{sp}^{2}\right)$ bonds $(1.425(2) / 1.457(2) \AA$ for $1 \mathbf{a}$ and 1.432(2)/1.452(2) $\AA$ for $\mathbf{1 b}$ ). These bond lengths are in agreement with known $p$-quinoidal sub-structures. ${ }^{18,22}$

To investigate the optoelectronic properties, UV/Vis absorption spectra of solutions of $\mathbf{1 a}$ and $\mathbf{1 b}$ in DCM were recorded and shown in Figure 3 a). The absorption of $\mathbf{1 a}, \mathbf{b}$ is strongly red-shifted compared to the parent IF and broad absorptions between 500 and $800 \mathrm{~nm}$ with local maxima at 
630 and $634 \mathrm{~nm}$ as well as global maxima at 676 and 682 $\mathrm{nm}$, respectively are found. No fluorescence was detected when excited with UV light as expected for PHs with an antiaromatic character. ${ }^{26}$

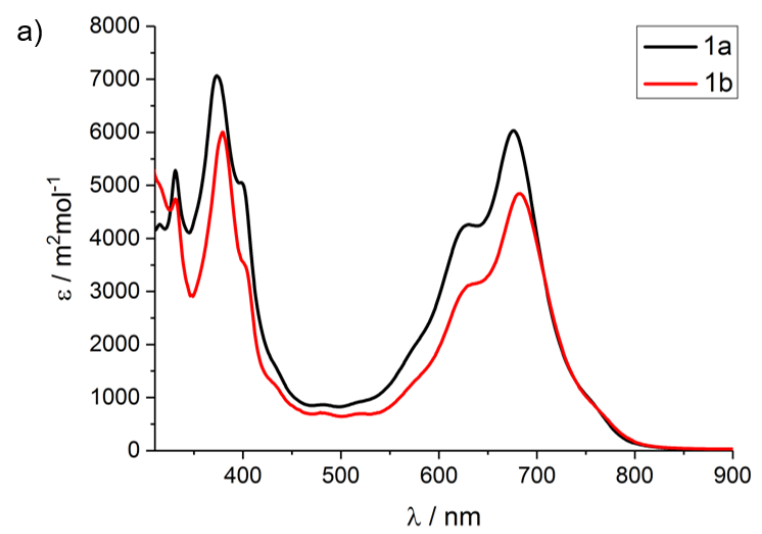

b)

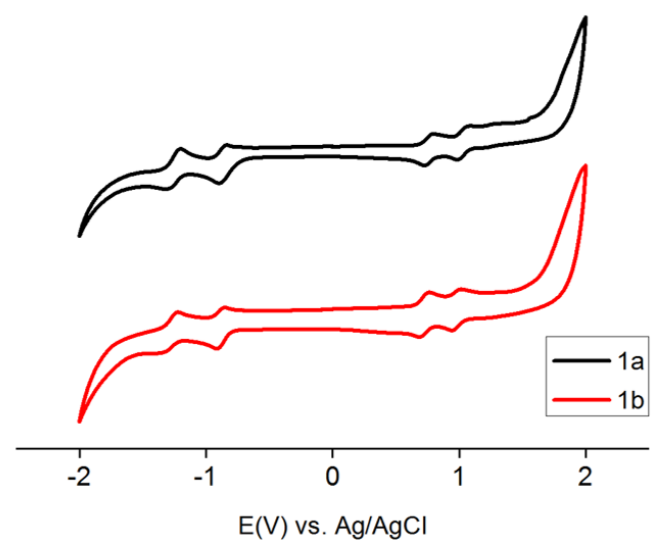

Figure 3. a) UV/Vis absorption spectra of 1a (black line) and $\mathbf{1 b}$ (red line) in DCM at $10^{-5}$ moll-1; $^{-1}$ b) cyclic voltamograms of $\mathbf{1 a}$ (black line) and $\mathbf{1 b}$ (red line) in potential range of $-\mathbf{2}$ to $2 \mathrm{~V}$

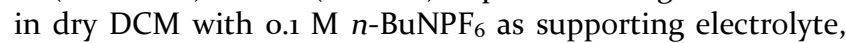
$\mathrm{Ag} / \mathrm{AgCl}$ was used as reference electrode, platinum as a working electrode and a Pt-wire as counter electrode performed at a scan rate of $50 \mathrm{mVs}^{-1}$.

The redox properties of $\mathbf{1 a}$ and $\mathbf{1 b}$ were investigated by cyclic voltammetry (CV) measurements (Figure $3 \mathrm{~b}$ )). IDP 1a shows two reversible oxidation waves with half wave potentials $E_{1 / 2,0 x}$ at 0.76 and $1.03 \mathrm{~V}$ and two reversible reduction waves with half-wave potentials $E_{1 / 2, \text { red }}$ at -0.86 and $-1.24 \mathrm{~V}$ (vs $\mathrm{Ag} / \mathrm{AgCl}$ ). Two reversible oxidation waves with $\mathrm{E}_{1 / 2,0 x}$ at 0.72 and $0.97 \mathrm{~V}$ and two reversible reduction waves with $E_{1 / 2 \text {,red }}$ at -0.88 and $-1.28 \mathrm{~V}$ were observed for compound $\mathbf{1 b}$. Thus, the HOMO/LUMO energy levels are estimated to be $-5.02 /-3.44 \mathrm{eV}$ and $-5.00 /-3.40 \mathrm{eV}$ for $\mathbf{1 a}$ and $\mathbf{1 b}$, respectively, on the basis of the onset potentials of the first oxidation/reduction waves.
The corresponding, electrochemical derived, energy gaps $\left(\Delta \mathrm{E}_{\mathrm{g}}\right)$ are 1.58 and $1.60 \mathrm{eV}$ for $\mathbf{1 a}$ and $\mathbf{1 b}$, respectively, which are in agreement with their calculated optical energy gaps (Table 1). Compared to the reported 6,12-

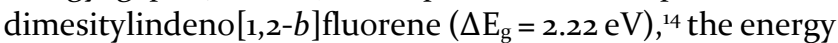
gap decreased by $0.6 \mathrm{eV}$ as the $\mathrm{HOMO}$ energy raised from $-5.78 \mathrm{eV}$ up to -5.02 and $-5.00 \mathrm{eV}$, for $\mathbf{1 a}$ and $\mathbf{1 b}$, respectively. ${ }^{22}$ The LUMO energy increased from $-3.56 \mathrm{eV}$ for the parent IF to -3.44 and $-3.40 \mathrm{eV}$ for $\mathbf{1 a}$ and $\mathbf{1 b}$, respectively.

The reversible oxidation found for $\mathbf{1 a}$ and $\mathbf{1 b}$ encouraged us to investigate the generation of the cation radical and dicationic species. First UV/Vis oxidation titration of both solutions in anhydrous dichloromethane (DCM) was performed with the one-electron-oxidant $\mathrm{AgSbF}_{6}$.
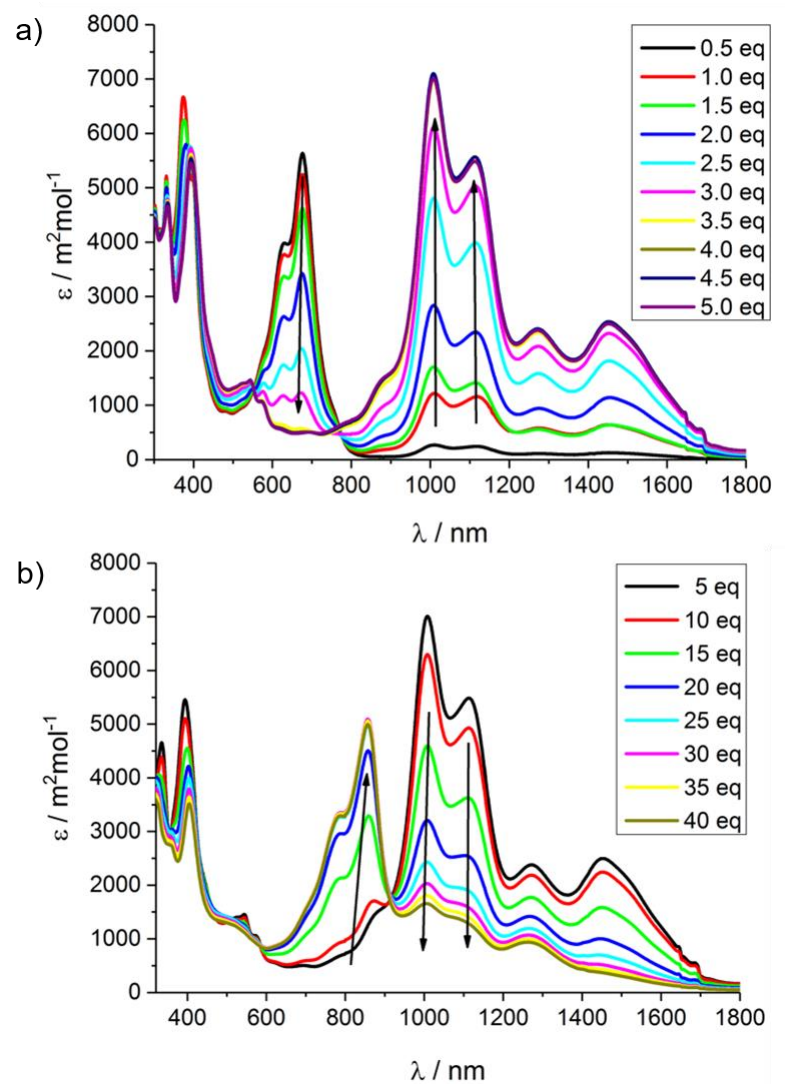

Figure 4. UV/Vis absorption titration spectra using a solution of one-electron-oxidant $\mathrm{AgSbF}_{6}$ in dry $\mathrm{DCM}$ at $10^{-5} \mathrm{moll}^{-1}$; UV/Vis spectra were directly measured after addition of the oxidant; a) UV/Vis absorption during titration of $\mathbf{1 a}$ into $\mathbf{1 a}^{\cdot+}$ by adding $0-4.5$ eq oxidant in steps of 0.5 eq; b) UV/Vis absorption during titration of $1 \mathbf{a}^{\cdot+}$ to $1 \mathbf{a}^{++}$by further adding up to 40 eq of $\mathrm{AgSbF}_{6}$.

Table 1. Experimental and calculated values of optoelectronic data 
Final edited form was published in "The Journal of Organic Chemistry" 139 (48), S. 6633 - 6639. ACS Publications. ISSN $1520-6904$. https://doi.org/10.1021/acs.joc.8b00925

$\begin{array}{lllllllll}\text { compd } & \begin{array}{l}\lambda_{\max }{ }^{a} \\ (\mathrm{~nm})\end{array} & \begin{array}{l}\text { opt. } \Delta \mathrm{E}_{\mathrm{g}}{ }^{b} \\ (\mathrm{eV})\end{array} & \begin{array}{l}\mathrm{E}_{\mathrm{HOMO}^{c}} \\ (\mathrm{eV})\end{array} & \begin{array}{l}\mathrm{E}_{\mathrm{LUMO}^{d}} \\ (\mathrm{eV})\end{array} & \begin{array}{l}\Delta \mathrm{E}_{\mathrm{g}}{ }^{e} \\ (\mathrm{eV})\end{array} & \begin{array}{l}\mathrm{E}_{\mathrm{HOMO}^{f}} \\ (\mathrm{eV})\end{array} & \begin{array}{l}\mathrm{E}_{\mathrm{LUMO}^{g}} \\ (\mathrm{eV})\end{array} & \begin{array}{l}\Delta \mathrm{E}_{\mathrm{g}}{ }^{h} \\ (\mathrm{eV})\end{array} \\ \mathbf{1 a} & 676 & 1.84 & -5.02 & -3.44 & 1.58 & -4.57 & -2.79 & 1.77 \\ \mathbf{1 b} & 682 & 1.82 & -5.00 & -3.40 & 1.60 & -4.51 & -2.74 & 1.77\end{array}$

${ }^{a}$ Absorption at maximum wavelength; ${ }^{b}$ optical energy gap calculated from the UV/Vis absorption maxima using the PlanckEinstein relation; ${ }^{c} \mathrm{HOMO}$ estimated from the onset potential of the first oxidation wave; ${ }^{d}$ LUMO estimated from the onset potential of the first reduction wave; ${ }^{e}$ energy gap calculated according to $\Delta \mathrm{E}_{\mathrm{g}}=\mathrm{E}_{\mathrm{HOMO}}-\mathrm{E}_{\mathrm{LUMO}} ;{ }^{f} \mathrm{HOMO}$ calculated by DFT Gaussian o9 package; ${ }^{g} \mathrm{LUMO}$ calculated by DFT Gaussian o9 package; ${ }^{h}$ energy gap calculated according to $\Delta \mathrm{E}_{\mathrm{g}}=\mathrm{E}_{\text {HOмо-}} \mathrm{E}_{\mathrm{LUMO}}$.

Addition of 1.0-2.o equivalents (eq) $\mathrm{AgSbF}_{6}$ to the solution of ra induced a strong bathochromic shift of the maximum absorption to $1007 \mathrm{~nm}$ and minor absorptions arose between 1050 and $1700 \mathrm{~nm}$ with local maxima at 1113, 1271 and $1452 \mathrm{~nm}$ as exemplified in Figure 4 a) for $1 \mathbf{a}$ (see Supporting Information, Figure $\mathrm{S}_{20}$ a) for $\mathbf{1 b}$ ). These absorptions can be attributed to the formation of radical cations $\mathbf{1 a}^{+}$, most likely paired with $\mathrm{SbF}_{6}{ }^{-}$as the counter ion. After addition of 4.5 eq $\mathrm{AgSbF}_{6}$, the initial IDP $\mathbf{1 a}$ was completely converted according to the vanished absorptions between 600 and $800 \mathrm{~nm}$. Upon further addition of an excess of $40 \mathrm{oeq} \mathrm{AgSbF}_{6}$, a hypsochromic shift to $858 \mathrm{~nm}$ (Figure $4 \mathrm{~b}$, see Supporting Information Figure S2o b)for 1b) was observed what we interpret as the formation of a dication $\mathbf{1 a}^{++}$. No further changes of the $\mathrm{UV} / \mathrm{Vis}$ absorption spectra were detected after addition of more than 50 eq $\mathrm{AgSbF}_{6}$ for both compounds.

Density functional theory (DFT) and time-dependent DFT (TD-DFT) calculation were performed using the Gaussian o9 package. The geometry of all the structures were optimized at the B3LYP level of theory with the 6${ }_{31} \mathrm{G}(\mathrm{d})$ basis set. TD-DFT calculation was performed on the neutral, radical cation and dication compounds in order to study the excited states. The graphical representation of the calculated UV/Vis spectra for $\mathbf{1 a}, \mathbf{1 a}^{++}, \mathbf{1 a}^{++}$and $\mathbf{1} \mathbf{b}, \mathbf{1}^{\cdot+}$, $\mathbf{l b}^{++}$and the shapes of the frontier orbital as well as the values for neutral structures in vacuo calculated by Gaussian o9 package are summarized in the Supporting Information (Figure $\mathrm{S}_{30}-\mathrm{S}_{35}$ ).

The HOMO and LUMO orbitals are mainly distributed around the $s$-indacene core as well as at the margin areas of the pyrene scaffold for both compounds $\mathbf{1 a}$ and $\mathbf{1 b}$ as pictured in Figure 5 for 1a (see Supporting Information Figure $\mathrm{S}_{25}-\mathrm{S}_{27}$ for $\mathbf{1 b}$ ). The DFT calculated energy gaps for $\mathbf{1 a}$ and $\mathbf{1 b}$ are $1.77 \mathrm{eV}$. These results are in agreement with the experimental data and are summarized together in Table 1. The calculated energy gaps are located in between the experimental UV/Vis and electrochemical results and closer to the optical derived values of 1.84 and $1.82 \mathrm{eV}$ for $\mathbf{1 a}$ and $\mathbf{1 b}$, respectively. The differences in energy gaps derived by calculation, absorption spectroscopy and CV may arise from polarization effects during the measurement in DCM.

To verify the antiaromatic feature at the internal $s$ indacene core, NICS(1) calculation using the GIAO B3LYP/6-311+G(2d,p) method have been performed. a)

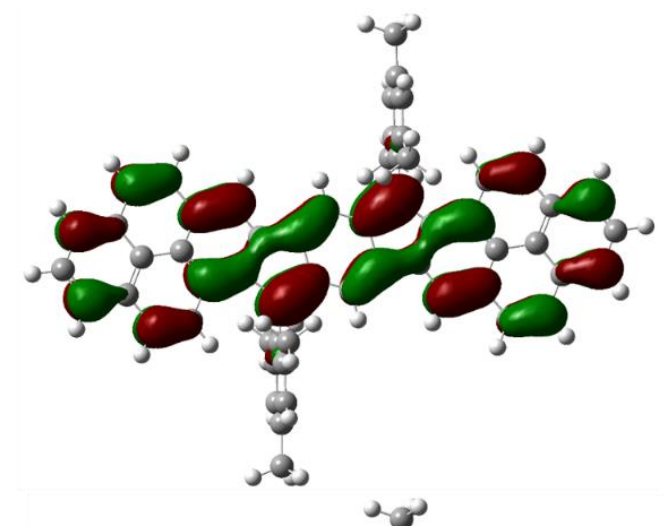

b)

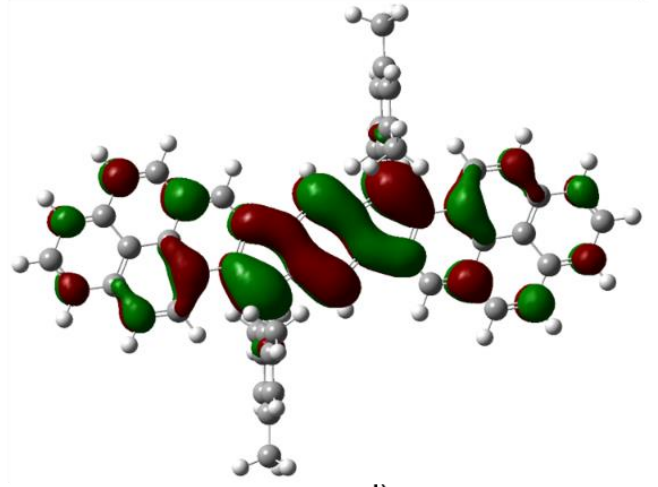

c)

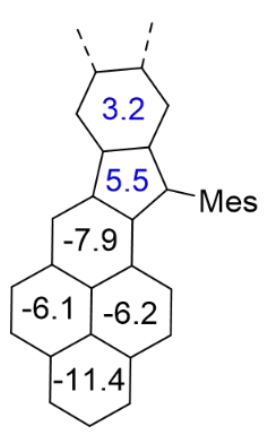

d)

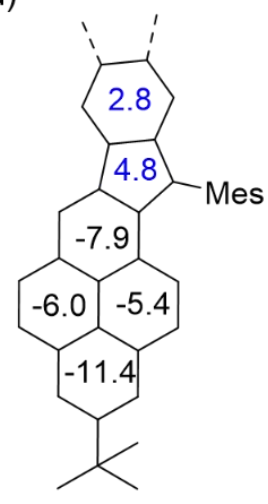

Figure 5. Visualization of the frontier orbitals and NICS calculation; a) HOMO 1a (-4.57 eV); b) LUMO 1a $(-2.79 \mathrm{eV}) \mathrm{c}$ ) $\operatorname{NICS}(\mathbf{1})$ values of $\mathbf{1 a}$; d) NICS(1) values of $\mathbf{1 b}$.

For $\mathbf{1 a}$ and $\mathbf{1 b}$, NICS values are positive at the fivemembered (5.5 and 4.8, respectively) and central sixmembered (3.2 and 2.8, respectively) rings, confirming the preserved antiaromaticity of the $s$-indacene unit (Figure 5 c), d)). The negative values for the outer pyrene units are in accordance with calculations by Jenneskens and confirm 
the proposed structure and electronic character of pyrenefused $s$-indacene. ${ }^{27}$

\section{CONCLUSION}

In summary, we present two novel antiaromatic $s$ indacenodipyrenes (IDPs) with large bathochromic shift compared to the parent IF and its derivatives. Photophysical and electrochemical measurements demonstrated that IDPs $\mathbf{1 a}$ and $\mathbf{1 b}$ possess absorption maxima approaching the NIR region combined with excellent redox behavior. The simple and scalable synthetic protocols towards antiaromatic $\mathrm{PHs}$ by combining two pyrene scaffolds with a functionalized benzene core enables the extension towards stable and $\pi$ expanded ladder-type polymers representing a repeating IF motive.

\section{EXPERIMENTAL SECTION}

General Methods. Unless otherwise stated, commercially available starting materials, catalysts, reagents and dry solvents were used without further purification. Reactions were performed using standard vacuum-line and Schlenk techniques. Purification of $\mathbf{4 a - b}$ and $\mathbf{5 a - b}$ was carried out under ambient conditions using reagent-grade solvents. Purification of $\mathbf{1 a - b}$ was carried out under argon conditions using dry and bubbled toluene and methanol. Column chromatography was performed on silica $\left(\mathrm{SiO}_{2}\right.$, particle size 0.063-0.200 mm purchased from VWR) or aluminium oxide $\left(\mathrm{Al}_{2} \mathrm{O}_{3}\right.$, Alox 90 active neutral, activity stage I, purchased from Merck KGaA). Silica coated aluminum sheets with fluorescence indicator (TLC Silica gel $60 \mathrm{~F}_{254}$ purchased from Merck KGaA) were used for thin layer chromatography. The starting materials $4 \mathbf{a}-\mathbf{b}^{[1]}$ and 2,5-dibromoterephtalaldehyde ${ }^{[2]}$ were synthesized according to literature procedures. HR-MALDI-TOF MS spectra were recorded on a Bruker Autoflex Speed MALDITOF MS (Bruker Daltonics, Bremen, Germany). All samples were prepared by mixing the analyte and the matrix, 1,8-dihydroxyanthracen-9(10H)-one (dithranol, purchased from Fluka Analytical, purity $>98 \%$ ), in the solid state. NMR Data were recorded on a Bruker AV-II 300 spectrometer operating at $300 \mathrm{MHz}$ for ${ }^{1} \mathrm{H}$ and $75 \mathrm{MHz}$ for ${ }_{13} \mathrm{C}$ and on a Bruker AV-III 600 spectrometer operating at $600 \mathrm{MHz}$ for ${ }^{1} \mathrm{H}$ and ${ }_{151} \mathrm{MHz}$ for ${ }^{13} \mathrm{C}$ with standard Bruker pulse programs at room temperature $(296 \mathrm{~K})$. Chemical shifts were referenced to $\delta_{\mathrm{TMS}}=0.00 \mathrm{ppm}\left({ }^{1} \mathrm{H},{ }^{13} \mathrm{C}\right)$. Chemical shifts $(\delta)$ are reported in ppm. Coupling constants $(J)$ are reported in Hz. Dichloromethane-d2 $(\delta$ $\left.\left({ }^{1} \mathrm{H}\right)=5.32 \mathrm{ppm}, \delta\left({ }^{13} \mathrm{C}\right)=53.8 \mathrm{ppm}\right)$, tetrachloroethane-d 2 $\left(\delta\left({ }^{1} \mathrm{H}\right)=5.91 \mathrm{ppm}, \delta\left({ }^{13} \mathrm{C}\right)=74.2 \mathrm{ppm}\right)$ or chloroform-d $1(\delta$ $\left.\left({ }^{1} \mathrm{H}\right)=7.26 \mathrm{ppm}, \delta\left({ }^{13} \mathrm{C}\right)=77.16 \mathrm{ppm}\right)$ were used as solvents. The following abbreviations are used to describe peak patterns as appropriate: $\mathrm{s}=$ singlet, $\mathrm{d}=$ doublet, $\mathrm{t}=$ triplet, $\mathrm{q}=$ quartet, $\mathrm{m}=$ multiplet. Dichloromethane- $\mathrm{d} 2$ (99,9 Atom\% D) was purchased from euriso-top, tetrachloroethane-d2 (99,6 Atom\% D) was purchased from Carl Roth GmbH and chloroform-d1 (99,8 Atom\% D) was purchased from deutero GmbH. UV/Vis-NIR absorption spectroscopy was conducted on an Agilent Technologies Cary Series 5000 using a $10 \mathrm{~mm}$ optical-path quartz cell at room temperature. Unless otherwise stated, a solution of the target compounds at a concentration of $10^{-5} \mathrm{moll}^{-1}$ in dichloromethane was measured. Fluorescence spectra were recorded at room temperature on a Perkin Elmer Fluorescence Spectrometer LS 55 using a $10 \mathrm{~mm}$ fluorescence quartz cell and argon-purged solutions of the respective compounds $\left(10^{-5} \mathrm{moll}^{-1}\right.$ in anhydrous dichloromethane). Cyclic voltammetry measurements were carried out on a $\mathrm{CHI} 76 \mathrm{o} \mathrm{E}$ potentiostat $(\mathrm{CH}$ Instruments, USA) in a three-electrode cell. Electrolyte solutions were prepared by solving $\left[n \mathrm{Bu}_{4} \mathrm{~N}\right]\left[\mathrm{PF}_{6}\right]$ o.1 $\mathrm{M}$ in dichloromethane and the experiments were performed with a scan rate of $50 \mathrm{mVs}^{-1}$ at room temperature. All measurements were recorded in argon-purged solutions of $\mathbf{1 a}-\mathbf{b}$ in anhydrous dichloromethane. A Pt-electrode and a Pt-wire were used as working and counter electrode, respectively. $\mathrm{Ag} / \mathrm{AgCl}$ (3 $\mathrm{M} \mathrm{KCl}$ solution) was used as reference electrode. All electrochemical measurements were referenced by adding an adequate amount of $\mathrm{Cp}_{2} \mathrm{Fe}$. The oxidation potential for ferrcocene $E_{1 / 2}\left(\mathrm{Cp}_{2} \mathrm{Fe} / \mathrm{Cp}_{2} \mathrm{Fe}^{+}\right)$ in dichloromethane was observed at $0.44 \mathrm{eV}$. Melting Points were determined on a Büchi Melting Point M-56o in a range of $50-400{ }^{\circ} \mathrm{C}$ with a temperature rate of $10^{\circ} \mathrm{Cmin}$ 1. Density functional theory (DFT) and time-dependent DFT (TD-DFT) calculation were performed using the Gaussian o9 Rev. A02 package. ${ }^{[3]}$ The geometry of all the structures were optimized at the B3LYP level of theory with the $6-31 \mathrm{G}(\mathrm{d})$ basis set. TD-DFT calculation has been performed on the neutral, radical cation and dication compounds in order to study the excited states.

Preparation of $\boldsymbol{s}$-indacenodipyrenes $\mathbf{1 a}, \mathbf{b}$. 2,5di(pyren-2-yl)terephthalaldehyde (5a). 2,5Dibromoterephthalaldehyde (162 mg, o.55 mmol, 1.0 eq), 4a (546 mg, $1.66 \mathrm{mmol}$, 3.0 eq) and $\mathrm{K}_{2} \mathrm{CO}_{3}$ (46o mg, 3.33 mmol, 6.0 eq) were added to a mixture of toluene $(9 \mathrm{ml})$, ethanol $(3 \mathrm{ml})$ and water $(3 \mathrm{ml})$ in a $25 \mathrm{~mL}$ Schlenk flask and purged for 30 minutes with argon. After the addition of $\mathrm{Pd}\left(\mathrm{PPh}_{3}\right)_{4}(128 \mathrm{mg}$, $0.11 \mathrm{mmol}$, o.2 eq) as catalyst, the reaction mixture was stirred under reflux at $90{ }^{\circ} \mathrm{C}$ for 20 hours in an oil bath. The reaction mixture was allowed to cool to room temperature and water $(50 \mathrm{ml})$ as well as chloroform (100 ml) were added. The organic phase was collected and all volatiles removed under reduced pressure. The remaining solid was suspended in methanol and filtered to give crude precursor $\mathbf{5}$ a as yellow powder (94\%, $278 \mathrm{mg}, 0.52 \mathrm{mmol}$ ), which was used without further purification. Due to the extreme low solubility of $5 \mathbf{a}$ in common NMR solvents such as deuterated dichloromethane- $\mathrm{d}_{2}$, chloroform- $\mathrm{d}_{1}$, tetrachloroethane- $\mathrm{d} 2$, tetrahydrofurane- $\mathrm{d}_{4}$, toluene- $\mathrm{d} 8$ or chlorobenzene- $\mathrm{d}_{5}$, a detailed spectroscopic NMR investigation was not possible. The precursor 5a was confirmed by high resolution mass spectrometry. HR-MS (MALDI-TOF): $\mathrm{m} / \mathrm{z}=534.1630$, calculated for $\mathrm{C}_{40} \mathrm{H}_{22} \mathrm{O}_{2}: \mathrm{m} / \mathrm{z}=534.1620$, error $=+1.87 \mathrm{ppm}$.

2,5-bis(7-(tert-butyl)pyren-2-yl)terephthalaldehyde (5b). 2,5-Dibromoterephthalaldehyde (50 mg, $0.17 \mathrm{mmol}$, $1.0 \mathrm{eq}$ ), 4b (197 mg, 0.51 mmol, 3.0 eq) and $\mathrm{K}_{2} \mathrm{CO}_{3}(142 \mathrm{mg}, 1.03$ mmol, 6.o eq) were added to a mixture of toluene $(3 \mathrm{ml})$, ethanol $(1 \mathrm{ml})$ and water $(1 \mathrm{ml})$ in a $10 \mathrm{ml}$ Schlenk flask and purged for 30 minutes with argon. After the addition of the 
catalyst $\mathrm{Pd}\left(\mathrm{PPh}_{3}\right)_{4}(39 \mathrm{mg}, 0.03 \mathrm{mmol}$, $0.2 \mathrm{eq})$, the reaction mixture was heated under reflux at $90^{\circ} \mathrm{C}$ for 20 hours in an oil bath. After cooling down to room temperature, the reaction was quenched by adding water (10o $\mathrm{ml})$. The aqueous phase was extracted three times with chloroform $(100 \mathrm{ml})$. The combined organic layers were dried over $\mathrm{MgSO}_{4}$, filtered and all volatiles were evaporated under reduced pressure. The remaining solid was suspended in methanol and filtered to yield precursor $\mathbf{5} \mathbf{b}$ as pale green powder $(96 \%, 105 \mathrm{mg}, 0.16 \mathrm{mmol})$, which was used without further purification. ${ }^{1} \mathrm{H}$ NMR $(300 \mathrm{MHz}$, tetrachloroethane-d 2$), \delta=10.12(\mathrm{~s}, 2 \mathrm{H}), 8.37(\mathrm{~s}, 2 \mathrm{H}), 8.25(\mathrm{~s}$, $4 \mathrm{H}), 8.21(\mathrm{~s}, 4 \mathrm{H}), 8.14(\mathrm{~d}, J=9.0 \mathrm{~Hz}, 4 \mathrm{H}), 8.08(\mathrm{~d}, J=9.0 \mathrm{~Hz}$, $\left.{ }_{4} \mathrm{H}\right), \quad 1.54 \quad(\mathrm{~s}, \quad 18 \mathrm{H}) \quad \mathrm{ppm} ;{ }^{13} \mathrm{C}$ NMR $(75 \mathrm{MHz}$, tetrachloroethane-d2), $\delta=192.6,150.3,145.4,137.0,133.8$, $131.4,131.3,129.3,127.4,126.4,124.5,123.4,122.6,35.6,32.2$ ppm; HR-MS (MALDI-TOF): $\mathrm{m} / \mathrm{z}=646.2892$, calculated for $\mathrm{C}_{48} \mathrm{H}_{38} \mathrm{O}_{2}: \mathrm{m} / \mathrm{z}=646.2872$, error $=+3.09 \mathrm{ppm}$.

8,18-dimesityl-s-indaceno[2,1-a:6,5-a']dipyrene

(1a).

Precursor 5a (250 mg, $0.47 \mathrm{mmol}$, 1.0 eq) was dissolved in $150 \mathrm{ml}$ tetrahydrofuran (THF) in a dry Schlenk flask and a solution of 2-mesityl magnesiumbromide in THF $(7.0 \mathrm{ml}$, 1.0 M, 7.00 mmol, 15.0 eq) was added slowly at room temperature. The mixture was stirred overnight, quenched by slow addition of water (100 $\mathrm{ml})$ and the aqueous phase extracted three times with chloroform $(100 \mathrm{ml})$ afterwards. The combined organic layers were dried over $\mathrm{MgSO}_{4}$, filtered and all volatiles evaporated under reduced pressure. The crude material was then transferred to a dry $50 \mathrm{ml}$ Schlenk flask and dissolved in $30 \mathrm{ml}$ dichloromethane. The mixture was cooled down to o ${ }^{\circ} \mathrm{C}$ and a solution of boron trifluoride diethyl etherate ( $230 \mu \mathrm{l}$, $1.87 \mathrm{mmol}, 4.0 \mathrm{eq}$ ) was added slowly in the course of $5 \mathrm{~min}$. The mixture was stirred for one hour and was carefully quenched with a saturated $\mathrm{NaHCO}_{3}$ solution (10 ml) afterwards. The aqueous phase was extracted three times with chloroform $(50 \mathrm{ml})$. The combined organic phases were again dried over $\mathrm{MgSO}_{4}$, filtered and all volatiles removed under reduced pressure. The obtained residue was filtered over a short silica plug (chloroform/iso-hexane: 1:4) to result in isomeric mixture of intermediated $\mathbf{6 a}$ (see Scheme 1 of manuscript) as light green solid. Intermediate 6a (20 mg, 0.027 mmol, 1.o eq) and 2,3-dichloro-5,6dicyano-1,4-benzoquinone (DDQ, $12 \mathrm{mg}$, 0.055 mmol, 2.0 eq) were redissolved in toluene $(3 \mathrm{ml})$ in a dry $10 \mathrm{ml}$ Schlenk flask and the mixture heated at $80^{\circ} \mathrm{C}$ in an oil bath. After two hours the reaction mixture was allowed to cool down to room temperature. Due to its low stability, the solution was quickly filtered through an aluminum oxide (neutral) column with dry toluene as eluent under argon atmosphere. All volatiles were evaporated under reduced pressure, the remaining solid was suspended in dry and argon-purged methanol and filtered to yield the bluegreenish target compound 1a in a good yield $(69 \%, 14 \mathrm{mg}$, $0.019 \mathrm{mmol})$. The intermediate $6 \mathbf{a}$ was confirmed by HRMALDI-TOF spectrometry $(\mathrm{m} / \mathrm{z}=738.3281$, calculated for $\mathrm{C}_{58} \mathrm{H}_{42}: \mathrm{m} / \mathrm{z}=738.3287$, error $\left.=0.81 \mathrm{ppm}\right)$. Due to the bad solubility $\left(1.3 \mathrm{mgml}^{-1}\right)$ of $\mathbf{1 b}$ the ${ }^{13} \mathrm{C}-\mathrm{NMR}$ measurements only show a low resolution. Full analytical data of target compound 1a: ${ }^{1} \mathrm{H}$ NMR (6oo MHz, tetrachloroethane-d2, after addition of hydrazine), $\delta=8.02(\mathrm{~s}, 2 \mathrm{H}), 7.91(\mathrm{~d}, J=7.4$ $\mathrm{Hz}, 2 \mathrm{H}), 7.83-7.79(\mathrm{~m}, 4 \mathrm{H}), 7.77(\mathrm{~d}, J=8.9 \mathrm{~Hz}, 2 \mathrm{H}), 7.72$ $(\mathrm{t}, J=7.5 \mathrm{~Hz}, 2 \mathrm{H}), 7.56(\mathrm{~d}, J=9.4 \mathrm{~Hz}, 2 \mathrm{H}), 7.2 \mathrm{O}(\mathrm{d}, J=9.3$ $\mathrm{Hz}, 2 \mathrm{H}), 7.07(\mathrm{~s}, 4 \mathrm{H}), 7.04(\mathrm{~s}, 2 \mathrm{H}), 2.44(\mathrm{~s}, 6 \mathrm{H}), 2.18(\mathrm{~s}, 12 \mathrm{H})$ ppm; ${ }^{13} \mathrm{C}$ NMR (151 MHz, tetrachloroethane-d2, after addition of hydrazine), $\delta=147.1,138.9,138.0,137.7,137.3$, 137.2, 137.0, 132.8, 132.0, 131.4, 131.2, $128.8(4 \mathrm{CH}), 128.7$ (2 $\mathrm{CH}), 128.6(2 \mathrm{CH}), 127.7(2 \mathrm{CH}), 127.6,126.3(2 \mathrm{CH}), 125.9$ (2 $\mathrm{CH}), 125.5(2 \mathrm{CH}), 123.8,122.8(2 \mathrm{CH}), 119.2(2 \mathrm{CH}), 118.5$ (2 $\mathrm{CH}), 117.1,116.9,116.7,21.8\left(2 \mathrm{CH}_{3}\right), 20.8\left(4 \mathrm{CH}_{3}\right)$ ppm; HRMS-MALDI-TOF: $\mathrm{m} / \mathrm{z}=736.3130$, calculated for $\mathrm{C}_{58} \mathrm{H}_{40}$ : $\mathrm{m} / \mathrm{z}=736.3130$, error $= \pm 0 \mathrm{ppm} ; \mathrm{mp}:>400{ }^{\circ} \mathrm{C}$.

2,12-di-tert-butyl-8,18-dimesityl-s-indaceno[2,1-a:6,5$\left.a^{\prime}\right]$ dipyrene ( $\mathbf{b} \boldsymbol{b}$ ). Precursor $5 \mathbf{b}$ (10o mg, o.17 mmol, 1.o eq) was dissolved in $50 \mathrm{ml}$ THF in a dry Schlenk flask and a solution of 2-mesityl magnesiumbromide in THF $(2.6 \mathrm{ml}$, 1.0 M, $2.55 \mathrm{mmol}, 15.0 \mathrm{eq}$ ) was added slowly at room temperature. The mixture was stirred overnight and quenched afterwards by slow addition of water $(50 \mathrm{ml})$. The aqueous phase was extracted three times with chloroform $(50 \mathrm{ml})$. The combined organic layers were dried over $\mathrm{MgSO}_{4}$, filtered and all volatiles evaporated under reduced pressure. The crude material was transferred to a dry $50 \mathrm{ml}$ Schlenk flask and dissolved in 20 $\mathrm{ml}$ dichloromethane. The mixture was cooled down to ${ }^{\circ} \mathrm{C}$ and a solution of boron trifluoride diethyl etherate $(85 \mu \mathrm{l}$, $0.68 \mathrm{mmol}, 4.0 \mathrm{eq}$ ) was added slowly in the course of $5 \mathrm{~min}$. The mixture was stirred for one hour and was carefully quenched by addition of a saturated $\mathrm{NaHCO}_{3}$ solution $(5$ $\mathrm{ml}$ ) afterwards. The aqueous phase was extracted three times with chloroform $(50 \mathrm{ml})$ and the resulting combined organic phases were dried over $\mathrm{MgSO}_{4}$, filtered and all volatiles removed under reduced pressure. The obtained residue was filtered over a short silica plug (chloroform/ihexane: 1:4) to give an isomeric mixture of intermediate $\mathbf{6 b}$ (see Scheme 1 in manuscript) as light green solid. 6b (12 mg, $0.014 \mathrm{mmol}, 1.0 \mathrm{eq})$ and 2,3-dichloro-5,6-dicyano-1,4benzoquinone (DDQ, $6 \mathrm{mg}$, $0.027 \mathrm{mmol}$, $2.0 \mathrm{eq}$ ) were dissolved in toluene $(2 \mathrm{ml})$ in a dry $10 \mathrm{ml}$ Schlenk flask and the mixture heated at $80^{\circ} \mathrm{C}$ in an oil bath. After two hours the reaction mixture was allowed to cool down to room temperature. Due to its low stability, the solution was quickly filtered through an aluminum oxide (neutral) column with dry toluene as eluent under argon atmosphere. All volatiles were evaporated under reduced pressure, the remaining solid was suspended in dry and argon-purged methanol and filtered to give the bluegreenish target compound $\mathbf{l b}$ in a good yield $(60 \%, 7 \mathrm{mg}$, $0.082 \mathrm{mmol}$ ). The intermediate $\mathbf{6 b}$ was confirmed by HRMALDI-TOF (measured: $\mathrm{m} / \mathrm{z}=850.4593$, calculated for $\mathrm{C}_{66} \mathrm{H}_{58}: \mathrm{m} / \mathrm{z}=850.4539$, error $\left.=6.35 \mathrm{ppm}\right)$. Due to the bad solubility $\left(1.3 \mathrm{mgml}^{-1}\right)$ of $\mathbf{1 b}$ the ${ }^{13} \mathrm{C}-\mathrm{NMR}$ measurements only show a low resolution. Full analytical data of target compound $\mathbf{l b}$ : ${ }^{1} \mathrm{H}$ NMR (6oo MHz, tetrachloroethane- $\mathrm{d} 2$, after addition of hydrazine), $\delta=7.97(\mathrm{~s}, 2 \mathrm{H}), 7.92(\mathrm{~d}, J=1.6$ $\mathrm{Hz}, 2 \mathrm{H}), 7.82(\mathrm{~d}, J=1.6 \mathrm{~Hz}, 2 \mathrm{H}), 7.78(\mathrm{~d}, J=9.0 \mathrm{~Hz}, 2 \mathrm{H})$, $7.74(\mathrm{~d}, J=9.0 \mathrm{~Hz}, 2 \mathrm{H}), 7.53(\mathrm{~d}, J=9.5 \mathrm{~Hz}, 2 \mathrm{H}), 7.15(\mathrm{~d}, J=$ 9.2 Hz, $2 \mathrm{H}), 7.07(\mathrm{~s}, 4 \mathrm{H}), 7.01(\mathrm{~s}, 2 \mathrm{H}), 2.44(\mathrm{~s}, 6 \mathrm{H}), 2.17(\mathrm{~s}$, $\left.{ }_{12} \mathrm{H}\right), \quad 1.41 \quad(\mathrm{~s}, 18 \mathrm{H}) \quad \mathrm{ppm}$; ${ }^{13 \mathrm{C}} \mathrm{NMR}(151 \mathrm{MHz}$, tetrachloroethane-d2, after addition of hydrazine), $\delta=$ 
$149.4(2 \mathrm{C})$, $147.0(2 \mathrm{C})$, 139.0 (2C), $138.0(2 \mathrm{C}), 137.6(2 \mathrm{C}), 137.2$ $(2 \mathrm{C})$, 137.0 (2C), $132.8(2 \mathrm{C}), 131.9(2 \mathrm{C}), 131.2(2 \mathrm{C}), 131.0\left({ }_{2} \mathrm{C}\right)$, $128.9(2 \mathrm{CH}), 128.7(2 \mathrm{CH}), 128.5(2 \mathrm{CH}), 127.9(2 \mathrm{CH}), 127.4$ (2C), $125.9(2 \mathrm{C}), 124.1(2 \mathrm{C}), 123.8(2 \mathrm{C}), 123.1(2 \mathrm{CH}), 122.9$ $(2 \mathrm{CH}), 122.7(2 \mathrm{CH}), 119.0(2 \mathrm{CH}), 118.3(2 \mathrm{CH}), 116.9(2 \mathrm{C}), 35.2$ (2C), 32.0 $\left(6 \mathrm{CH}_{3}\right), 21.8\left({ }_{2} \mathrm{CH}_{3}\right), 20.8\left({ }_{4} \mathrm{CH}_{3}\right)$ ppm; HR-MS (MALDI-TOF): $\mathrm{m} / \mathrm{z}=848.4393$, calculated for $\mathrm{C}_{66} \mathrm{H}_{56}: \mathrm{m} / \mathrm{z}$ $=848.4382$, error $=+1.30 \mathrm{ppm}$; $\mathrm{mp}:>400{ }^{\circ} \mathrm{C}$.

\section{ASSOCIATED CONTENT}

The Supporting Information is available free of charge on the ACS Publications website.

HR-MALDI-TOF spectra for 1a,b. Copies of the ${ }^{1} \mathrm{H}$-and ${ }^{13} \mathrm{C}$ NMR spectra for $\mathbf{5 a}, \mathbf{b}$ and $\mathbf{1 a}, \mathbf{b}$. Single-crystal X-ray data (CIF) for $\mathbf{1 a}, \mathbf{b}$. UV/Vis absorption spectra for $\mathbf{1 a}, \mathbf{1 a}^{\mathbf{*}}, \mathbf{1} \mathbf{a}^{++}$and $\mathbf{1 b}$, $\mathbf{1 b}^{\mathbf{*}}, \mathbf{1} \mathbf{b}^{++}$. Fluorescence emission spectra and cyclic voltamograms for $\mathbf{1 a}, \mathbf{b}$. Computational data for $\mathbf{1 a}, \mathbf{1 a}^{\cdot+}, \mathbf{1 a}^{++}$ and $\mathbf{1 b}, \mathbf{1 b}^{\cdot+}, \mathbf{1 b}^{++}$.

\section{AUTHOR INFORMATION}

\section{Corresponding Author}

*E-Mail: xinliang.feng@tu-dresden.de

*E-Mail: reinhard.berger@tu-dresden.de.

\section{Author Contributions}

The manuscript was written through contributions of all authors. All authors have given approval to the final version of the manuscript.

\section{Notes}

The authors declare no competing financial interest.

\section{ACKNOWLEDGMENT}

This project has received funding from the European Union's Horizon 2020 research and innovation program under grant agreement No 696656 (Graphene Flagship Core1), the Center for Advancing Electronics Dresden (cfaed), the European Social Fund, and the Federal State of Saxony (ESF-Project “GRAPHD”, TU Dresden. We thank Dr. Tilo Lübken (Dresden University of Technology) for NMR measurements. Prof. Dr. Jan J. Weigand thanks the DFG for funding a diffractometer (INST 269/618-1).

\section{REFERENCES}

1. Zeng, Z.; Shi, X.; Chi, C.; Lopez Navarrete, J. T.; Casado, J.; Wu, J., Pro-aromatic and anti-aromatic $\pi$ conjugated molecules: an irresistible wish to be diradicals. Chem. Soc. Rev. 2015, 44, 6578-6596.

2. Chase, D. T.; Rose, B. D.; McClintock, S. P.; Zakharov, L. N.; Haley, M. M., Indeno[1,2-b]fluorenes: fully conjugated antiaromatic analogues of acenes. Angew. Chem. Int. Ed. 2011, 50, 1127-1130.

3. Sun, Z.; Zeng, Z.; Wu, J., Zethrenes, extended pquinodimethanes, and periacenes with a singlet biradical ground state. Acc. Chem. Res. 2014, 47, 2582-2591.

4. Nishinaga, T.; Ohmae, T.; Aita, K.; Takase, M.; Iyoda, M.; Arai, T.; Kunugi, Y., Antiaromatic planar cyclooctatetraene: a strategy for developing ambipolar semiconductors for field effect transistors. Chem. Commun. 2013, 49, 5354-5356.
5. $\quad$ Das, A.; Müller, T.; Plasser, F.; Lischka, H., Polyradical Character of Triangular Non-Kekulé Structures, Zethrenes, $p$-Quinodimethane-Linked Bisphenalenyl, and the Clar Goblet in Comparison: An Extended Multireference Study. J. Phys. Chem. A 2016, 120, 1625-1636.

6. Das, S.; Wu, J. 9. Polycyclic Hydrocarbons with an Open-Shell Ground State. In Chemistry of Carbon

Nanostructures; Müllen, K.; Feng, X.; De Gruyter, 2017, pp 253-288.

7. Shimizu, A.; Tobe, Y., Indeno[2,1-a]fluorene: An AirStable ortho-Quinodimethane Derivative. Angew. Chem. Int. Ed. 2011, 50, 6906-6910.

8. Li, Y.; Huang, K.-W.; Sun, Z.; Webster, R. D.; Zeng, Z.; Zeng, W.; Chi, C.; Furukawa, K.; Wu, J., A kinetically blocked 1,14:11,12-dibenzopentacene: a persistent triplet diradical of a non-Kekulé polycyclic benzenoid hydrocarbon. Chem. Sci. 2014, 5, 1908-1914.

9. Das, S.; Lee, S.; Son, M.; Zhu, X.; Zhang, W.; Zheng, B.; Hu, P.; Zeng, Z.; Sun, Z.; Zeng, W.; Li, R.-W.; Huang, K.W.; Ding, J.; Kim, D.; Wu, J., para-Quinodimethane-Bridged Perylene Dimers and Pericondensed Quaterrylenes: The Effect of the Fusion Mode on the Ground States and Physical Properties. Chem. Eur. J. 2014, 20, 11410-11420.

10. Ohashi, K.; Kubo, T.; Masui, T.; Yamamoto, K.;

Nakasuji, K.; Takui, T.; Kai, Y.; Murata, I., 4,8,12,16-Tetra-tertbutyl-s-indaceno[1,2,3-cd:5,6,7-c'd']diphenalene: A Four-

Stage Amphoteric Redox System. J. Am. Chem. Soc. 1998, 120, 2018-2027.

11. Li, Y.; Heng, W. K.; Lee, B. S.; Aratani, N.; Zafra, J. L.; Bao, N.; Lee, R.; Sung, Y. M.; Sun, Z.; Huang, K. W.; Webster, R. D.; Lopez Navarrete, J. T.; Kim, D.; Osuka, A.; Casado, J.; Ding, J.; Wu, J., Kinetically blocked stable heptazethrene and octazethrene: closed-shell or open-shell in the ground state? J. Am. Chem. Soc. 2012, 134, 14913-14922. 12. Shimizu, A.; Hirao, Y.; Matsumoto, K.; Kurata, H.; Kubo, T.; Uruichi, M.; Yakushi, K., Aromaticity $\pi$-bond covalency: prominent intermolecular covalent bonding interaction of a Kekulé hydrocarbon with very significant singlet biradical character. Chem. Commun. 2012, 48, 56295631.

13. Tobe, Y., Quinodimethanes Incorporated in NonBenzenoid Aromatic or Antiaromatic Frameworks. Top. Curr. Chem. 2018, 376, 12.

14. Chase, D. T.; Fix, A. G.; Kang, S. J.; Rose, B. D.; Weber, C. D.; Zhong, Y.; Zakharov, L. N.; Lonergan, M. C.; Nuckolls, C.; Haley, M. M., 6,12-Diarylindeno[1,2-b]fluorenes: Syntheses, Photophysics, and Ambipolar OFETs. J. Am. Chem. Soc. 2012, 134, 10349-10352.

15. Anthony, J. E., The larger acenes: versatile organic semiconductors. Angew. Chem. Int. Ed. 2008, 47, 452-483.

16. Anthony, J. E., Functionalized Acenes and Heteroacenes for Organic Electronics. Chem. Rev. 2oo6, 106, 5028-5048.

17. Wu, J.; Pisula, W.; Müllen, K., Graphenes as Potential Material for Electronics. Chem. Rev. 2007, 107, 718747.

18. Frederickson, C. K.; Zakharov, L. N.; Haley, M. M., Modulating Paratropicity Strength in Diareno-Fused Antiaromatics. J. Am. Chem. Soc. 2016, 138, 16827-16838. 19. Petersen, J. F.; Frederickson, C. K.; Marshall, J. L.; Rudebusch, G. E.; Zakharov, L. N.; Hammerich, O.; Haley, M. M.; Nielsen, M. B., Expanded Indacene-Tetrathiafulvalene Scaffolds: Structural Implications for Redox Properties and Association Behavior. Chem. Eur. J. 2017, 23, 13120-13130. 
2o. Marshall, J. L.; Uchida, K.; Frederickson, C. K.;

Schutt, C.; Zeidell, A. M.; Goetz, K. P.; Finn, T. W.; Jarolimek, K.; Zakharov, L. N.; Risko, C.; Herges, R.; Jurchescu, O. D.;

Haley, M. M., Indacenodibenzothiophenes: synthesis, optoelectronic properties and materials applications of molecules with strong antiaromatic character. Chem. Sci. 2016, 7, 5547-5558.

21. Marshall, J. L.; O’Neal, N. J.; Zakharov, L. N.; Haley, M. M., Synthesis and Characterization of Two Unsymmetrical Indenofluorene Analogues: Benzo[5,6]-sindaceno[1,2- $b]$ thiophene and Benzo[5,6]-s-indaceno[2,1b]thiophene. J. Org. Chem. 2016, 81, 3674-3680.

22. Liu, J.; Ma, J.; Zhang, K.; Ravat, P.; Machata, P.; Avdoshenko, S.; Hennersdorf, F.; Komber, H.; Pisula, W.; Weigand, J. J.; Popov, A. A.; Berger, R.; Müllen, K.; Feng, X., $\pi$-Extended and Curved Antiaromatic Polycyclic Hydrocarbons. J. Am. Chem. Soc. 2017, 139, 7513-7521. 23. Crawford, A. G.; Liu, Z.; Mkhalid, I. A.; Thibault, M. H.; Schwarz, N.; Alcaraz, G.; Steffen, A.; Collings, J. C.; Batsanov, A. S.; Howard, J. A.; Marder, T. B., Synthesis of 2and 2,7-functionalized pyrene derivatives: an application of selective C-H borylation. Chem. Eur. J. 2012, 18, 5022-5035.

24. Tian, H.; Yang, X.; Chen, R.; Zhang, R.; Hagfeldt, A.; Sun, L., Effect of Different Dye Baths and Dye-Structures on the Performance of Dye-Sensitized Solar Cells Based on Triphenylamine Dyes. J. Phys. Chem. C 2008, 112, 11023-11033. 25. Initially solutions of $\mathbf{1 a}$ and $\mathbf{1 b}$ only showed broad signals in the aromatic area (see Supporting Information) what we attribute to the presence of trace amounts of radical impurities arising from immediate oxidation processes. 26. Frederickson, C. K.; Rose, B. D.; Haley, M. M., Explorations of the Indenofluorenes and Expanded Quinoidal Analogues. Acc. Chem. Res. 2017, 50, 977-987. 27. Havenith, R. W. A.; van Lenthe, J. H.; Dijkstra, F.; Jenneskens, L. W., Aromaticity of Pyrene and Its Cyclopentafused Congeners Resonance and NICS Criteria. An Ab Initio Valence Bond Analysis in Terms of Kekulé Resonance Structures. J. Phys. Chem. A 2001, 105, 3838-3845. 